\title{
A Case of Familial Intrahepatic Cholestasis
}

\author{
Minoru Hirooka and Tadasi Ohno \\ Department of Pediatrics (Dr. M. Hirooka), \\ Akita Central Hospital, Akita
}

\begin{abstract}
A case of intrahepatic cholestasis with mental and growth retardation, which was considered to be familial, was presented.

The jaundice appeared at the age of 6 months, being preceded by marked steatorrhea, and persisted throughout his life with fluctuation. He died of acute pneumonia after a laparotomy at 2 years 6 months.

The patient had marked itching and steatorrhea which were probably manifestations of bile salt retention, acholic stools, and short stubby hands and foots with thickened and brownish skin.

Biochemical characteristics of the serum were hyperbilirubinemia (over half being conjugated), moderately elevated alkaline phosphatase, slightly elevated GOT and GPT activities and $\alpha_{2}-$ and $\beta$-globulins, and normal to subnormal cholesterol.

There were also marked retention of B.S.P., presence of bilirubin in the urine and decreased fecal excretion of bilirubin and bile salts. Analysis of bile salts in the serum indicated an increase of cholic acid. Normal intra- and extrahepatic biliary passage was confirmed at operation and at autopsy. Light microscopic examination of the liver revealed periportal fibrosis and bile thrombi in the bile canaliculi, and electron microscopic examination of the liver revealed distortion of mitochondrial limiting membrane, dilatation of the bile canaliculi, blunted and diminished microvilli of the canalicular membrane and existence of a number of encapsulated bodies with a speckled appearance of obscure origin.

These conditions of our patient are considered to be similar to those of patients, which have been recently reported by Clayton et al. (1965), Gray et al. (1966) and Juberg et al. (1966), except for some minor differences.
\end{abstract}

Recently, a new form of intrahepatic cholestasis ${ }^{1}$ has been identified as a fundamental defect probably due to the difficulty in bile excretion. In 1965, Clayton et al. ${ }^{1}$ reported a fatal form of intrahepatic cholestasis, which was observed in 6 members of 4 Amish sibships. The clinical and biochemical characteristics of these cases were early onset of loose foul-smelling stools, attacks of jaundice which first appeared from one to 8 months after the onset of gastrointestinal symptoms, hepatosplenomegaly, dwarfism, hyperbilirubinemia (over half being direct-reacting pigment), elevated serum alkaline phosphatase, hypoprothrombinemia and normal to subnormal serum cholesterol.

Since then, similar cases have been reported by Gray and Saunders and Juberg et al. ${ }^{3}$

Received for publication, October 12, 1967. 
Gray et $a l .^{2}$ described 2 sisters, who died from a similar malignant variety of intrahepatic cholestasis, and Juberg et $a ._{.}{ }^{3}$ also reported 4 siblings with similar onset and progression of intrahepatic cholestasis.

These severe forms of intrahepatic cholestasis appearing in infancy and progressive in nature apparently differed from Rotor's syndrome and DubinJohnson syndrome $e^{4,5}$ in the symptoms, laboratory findings and liver histology.

The purpose of this report is to describe more severe cases of the disorder probably similar to those mentioned above, and further to emphasize that this disorder probably represents a new disease entity, which is not limited to one race or one family.

\section{Case Report}

History. The boy, the third of the siblings, was born by cesarean section on January 20 , 1963, after a normal full term pregnancy. Birth weight was $3,300 \mathrm{~g}$. His parents were Japanese and were not related. His mother had not been jaundiced. There were 3 siblings. The first sister was healthy and had no history of jaundice. However, the second sister, who had had neonatal jaundice lasting for 50 days, was noticed to have jaundice again at the age of 8 months and admitted to our clinic. On admission, this sister was extremely malnourished and markedly jaundiced, weighing only $4,850 \mathrm{~g}$. The abdomen was distended, and the liver was palpable $2 \mathrm{~cm}$ below the costal margin. The spleen was not felt. The stools were light yellow to gray. Urinalysis showed positive reaction for bilirubin and negative one for urobilinogen. The liver function tests indicated markedly increased serum bilirubin levels (total, $38.3 \mathrm{mg} / 100 \mathrm{ml}$; conjugated form, $14.8 \mathrm{mg} / 100 \mathrm{ml}$; unconjugated form, $23.5 \mathrm{mg} / 100 \mathrm{ml}$ ), slightly elevated glutamic oxaloacetic transaminase (64 units), glutamic pyruvic transaminase ( 41 units) and normal zink turbidity test (6.6 units). Her jaundice varied in intensity throughout the course and died of the disease at the age of one year.

The present patient visited a well-baby clinic at the age of 50 days, but no abnormality was pointed out. At the age of 3 months, stunted growth was noticed, and at the age of 4 months, he was found suffering from severe ricket in our clinic. Vitamin $D$ was given immediately in a dialy dose of 4000 I.U., and marked improvement resulted 2 months later.

At the age of 6 months, he was noticed to have jaundice, and admitted to our clinic on July 18, 1963, for detailed examination.

On admission, he was markedly malnourished, weighing 4,640 g and measuring $57 \mathrm{~cm}$ (normal values for 6 months old male infants, 7,670 g and $65.5 \mathrm{~cm}$ ) (Fig. 1), moderately jaundiced, and complained of marked pruritus. The fontanel was widely open and rosary was marked. The chest was normal. The abdomen was distended, showing slight dilatation of the superficial veins toward the upper region. The liver with smooth surface was palpable $6 \mathrm{~cm}$ below the costal margin. The spleen was not felt. The hands and feet had short and stubby appearance. No pathological reflexes were elicited.

Laboratory studies on admission (Table 1): tuberculin and Wassermann reactions were negative. The erythrocyte count was $3,700,000 / \mathrm{mm}^{3}$, hemoglobin $10.6 \mathrm{~g} / 100 \mathrm{ml}$, and hematocrit $32 \%$. The leucocyte count was $12,000 / \mathrm{mm}^{3}$, consisting of $24 \%$ neutrophils $(6 \%$ non-segmented neutrophils), $72 \%$ lymphocytes, and $4 \%$ eosinophils. The platelet count was $28.8 \times 10^{4} / \mathrm{mm}^{3}$. Bone marrow examination revealed normal cellularity. The bleeding time and red cell fragility test were normal.

Urinalysis showed negative results for protein, sugar and urobilinogen and positive reaction for bilirubin, of which excretion was $11.2 \mathrm{mg}$ per day. Microscopic examination of the urinary sediment was normal.

Acholic and bulky stools showed, positive reactions to Sudan III stain and Lugol reaction. No bile salts and lowered urobilinogen content $(0.7 \mathrm{mg} /$ day $)$ were detected. 


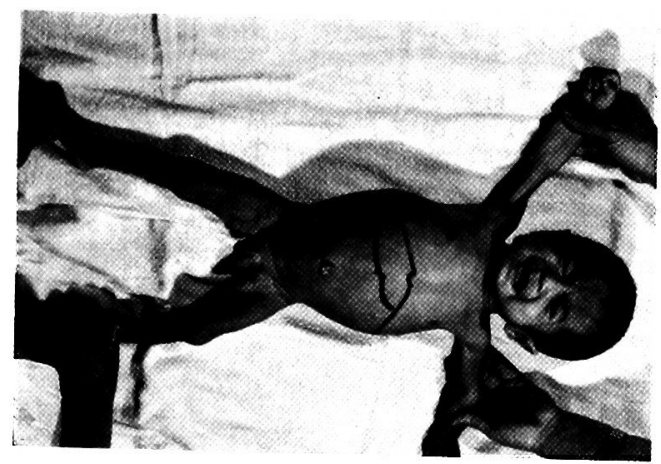

Fig. 1. The patient at the age of one year.

Electrolytes in the serum were as follows: sodium, $144 \mathrm{mEq} / 1$; potassium, $4.4 \mathrm{mEq} / 1$; chloride, $105 \mathrm{mEq} / \mathrm{l}$; calcium $4.6 \mathrm{mEq} / 1$; and phosphorus, $5.0 \mathrm{mg} / 100 \mathrm{ml}$.

The blood sugar, NPN, cholesterol, total lipid, phospholipid, and serum amylase were all within normal limits (Table 1).

The serum protein was $6.8 \mathrm{~g} / 100 \mathrm{ml}$, consisting of $50.7 \%$ albumin, $4.8 \% a_{1}$-globulin, $14.0 \% \quad \alpha_{2}$-globulin, $20.4 \% \quad \beta$-globulin, and $10.1 \% \quad \gamma$-globulin.

Representative liver function tests were given in Table 1 .

The serum bilirubin was $9.0 \mathrm{mg} / 100 \mathrm{ml}$ in the total, consisting of $6 \mathrm{mg} / 100 \mathrm{ml}$ in conjugated form and $3.0 \mathrm{mg} / 100 \mathrm{ml}$ in unconjugated form. Glutamic oxaloacetic transaminase (GOT), glutamic pyruvic transaminase (GPT) activities and alkaline phosphatase in the serum were slightly or moderately elevated. Zinc turbidity test, thymol turbidity test and cephalin cholesterol flocculation were all within normal limits.

B.S.P test was definitely abnormal, showing marked retention of the dye even after 180 minutes as shown in Fig. 2.

By using a simple solvent-partition method for measurement of free and conjugated bilirubin in serum reported by Eberlein ${ }^{6}$ (1960), monoglucuronide was found to be $3.8 \mathrm{mg} /$ $100 \mathrm{ml}$; diglucuronide, $4.2 \mathrm{mg} / 100 \mathrm{ml}$; and free bilirubin, $1.4 \mathrm{mg} / 100 \mathrm{ml}$. Quantitative estimation of bile salts in the serum by Kier method ${ }^{7}$ showed an increase of cholic acid $(12.4 \mathrm{mg} / 100 \mathrm{ml})$ and almost normal level of deoxy-cholic acid $(20.0 \mathrm{mg} / 100 \mathrm{ml})$. Enzymes in duodenal juice such as trypsin, diastase and lipase gave normal values, as shown in Table 1, but Pettenkofer's test was positive-negative.

By administration of magnesium sulfate or olive oil, no thickened B-bile but thin light yellow bile was obtained, indicating 5 units of ictrus index. The cystic bile obtained at the time of operation was also light yellow-brown and indicated low bilirubin level of $9.5 \mathrm{mg} / 100 \mathrm{ml}$, but normal values of electrolytes, GOT and GPT activities. Only cholic

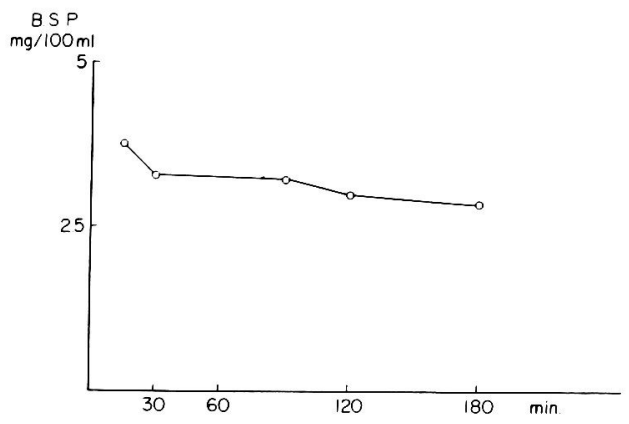

Fig. 2. B.S.P. test $(5 \mathrm{mg} / \mathrm{kg})$. 
TABLE 1. Laboratory results

Hematologic studies

Erythrocyte counts

Hemoglobin $(\mathrm{g} / 100 \mathrm{ml})$

Hematocrit $(\%)$

Leukocyte count

Differential counts (\%)

Neutrophils

Lymphocytes

Monocytes

Eosinophils

Platelet count

Bleeding time ( $\mathrm{min}$ )

Red cell fragility (max)

(min)

Urine

Protein

Sugar

Urobilinogen

Bilirubir

Acetone

Amylase

Sediment

Bilirubin (mg/day) May 29, 1964

Urobilinogen (")

Creatine (" )

Creatinine (" )

Feces: acholic bulky

Occult blood

Parasite

Sudan III stain

Lugol reaction

Schmidt reaction

Blood

Urobilinogen (mg/day)

Total serum protein $(\mathrm{g} / 100 \mathrm{ml})$

Albumin $(\%)$

$a_{1}$-Globulin $(\%)$

$\alpha_{2}$-Globulin $(\%)$

$\beta$-Globulin $(\%)$

$\alpha$-Globulin $(\%)$

$\mathrm{Na}(\mathrm{mEq} / \mathrm{L})$

$\mathrm{K}(\mathrm{mEq} / \mathrm{L})$

$\mathrm{Cl}(\mathrm{mEq} / \mathrm{L})$

$\mathrm{Ca}(\mathrm{mEq} / \mathrm{L})$

$\mathrm{P}(\mathrm{mg} / 100 \mathrm{ml})$

Blood sugar $(\mathrm{mg} / 100 \mathrm{ml})$

Non-protein-nitrogen $(\mathrm{mg} / 100 \mathrm{ml})$

Total lipid $(\mathrm{mg} / 100 \mathrm{ml})$

Phospholipid P (mg/100 ml)

Serum amylase (U)

Cholesterol $(\mathrm{mg} / 100 \mathrm{ml})$

Liver function tests

Bilirubin total $\begin{array}{ll}\text { conjugated form } & (\mathrm{mg} / 100 \mathrm{ml}) \\ \text { unconjugated form } & (\mathrm{mg} / 100 \mathrm{ml})\end{array}$

Glutamic pyruvic transaminase (U)

Glutamic oxaloacetic transaminase (U)

Zink sulfate turbidity (U)

Thymol turbidity (U)
$370 \times 1024$

10.6

32

12,000

24

7

2

4

$28.8 \times 10^{4}$

$1^{\prime} 30^{\prime \prime}$

0.40

0.32

$(-)$

$(-)$

(-)

(t)

(-)

$2^{5}$

Normal

11.2

1.1

31.2

760.0

$(-)$

(-)

(H)

(+)

(t)

0.7

6.8

50.7

4.8

14.0

20.4

10.1

144

4.4

105

4.6

5.0

90.0

32.7

$676 \mathrm{mg} / 100 \mathrm{ml}$

$$
2^{5} .^{2}
$$

135

9.0

6.0

3.0

25

60

6.4

3.8 
Table 1. Continued

Cephalin cholesterol flocculation

Alkaline phosphatase (Bodansky U)

B.S.P. $30^{\prime}(\%)$

$180 \%$ (\%)

Duodenal juice

$\mathrm{pH}$

Trypsin (U)

Diastase (U)

Lipase $(\mathrm{N} / 20 \mathrm{NaOH})(\mathrm{ml})$

Pettenkofer's test

Bile obtained from gall bladder

Bilirubin total $(\mathrm{mg} / 100 \mathrm{ml})$ conjugated $(\mathrm{mg} / 100 \mathrm{ml})$ unconjugated $(\mathrm{mg} / 100 \mathrm{ml})$

Alkaline phosphatase (Bodansky U)

Glutamic oxaloacetic transaminase (U)

Glutamic pyruvic transaminase (U)

$\mathrm{Na}(\mathrm{mEq} / \mathrm{L})$

$\mathrm{Cl} \quad(\mathrm{mEq} / \mathrm{L})$

$\mathrm{Ca} \quad(\mathrm{mEq} / \mathrm{L})$

Cholesterol

Absorption tests

Stool

Fat in dried stool (\%)

Fat excreted in stool per day $(\mathrm{g})$

d-Xylose absorption test ( $5 \mathrm{~g}$ per sq. meter of body surface)

Urinary excretion in 5 hours

Galactose absorption test ( $7.5 \mathrm{~g}$ per orally)

Urinary excretion in 5 hours

$(-)$

122

34

$29]$

8.3

$2^{8}$

$2^{12}$

1.3

(士)

9.5

7.8

1.7

3

18

18

136

120

5.3

2.4

84

43

16.5

0.22

$0.5>$

57

48

7.1

22

47

1.0

0.2

Others

Urinary 17-OHCS (mg/24 hr)

Glucose tolerance test $(1.5 \mathrm{~g} / \mathrm{kg}$ per os)

Before (mg/100ml)

$30^{\prime}$

$60^{\prime}$

$120^{\prime}$

$180^{\prime}$

$240^{\prime}$

$\mathrm{Cl}$ in the sweat $(\mathrm{mEq} / \mathrm{L})$

$\mathrm{Na}$ in the sweat $(\mathrm{mEq} / \mathrm{L})$

Amino acid analysis by paperchromatography

Serum fatty acid analysis by gaschromato-

graphy

Myristic acid

$\mathrm{C} 14_{0}$

Palmitic acid

$\mathrm{Cl} 6_{1}$ 
TABLE 1. Continued

\begin{tabular}{cc|rc}
\multirow{3}{*}{ Stearic acid } & $\mathrm{Cl}_{0}$ & 12 & 24.0 \\
& $\mathrm{Cl8}_{1}$ & 255 & 113.9 \\
& $\mathrm{Cl8} 8_{2}$ & 100 & 100 \\
Chromosome analysis & $\mathrm{C} 20_{4}$ & \multicolumn{2}{|c}{ Normal }
\end{tabular}

acid was detected out of bile salt compounds by gaschromatography.

There was marked steatorrhea. Fat content of the stool was $76-84 \%$ in dry weight and daily fecal fat excretion amounted to $43 \mathrm{~g}$ per day. ${ }^{131} \mathrm{I}$ triolein and ${ }^{131} \mathrm{I}$ oleic acid absorption tests also afforded the evidence of steatorrhea. d-Xylose absorption test indicated slight impairment, showing excretion of $165 \%$ in 5 hours. Galactose and RISA absorption tests were all within normal limits.

The results of endocrine studies were all within normal limits and chromosomal study revealed a normal karyotype with 46 chromosomes.

Amino acid analysis of the urine by paperchromatography gave normal patterns and total serum fatty acid analysis by gaschromatography indicated a comparative increase of endogenous fatty acids such as myristic acid, palmitic acid and stearic acid etc. Sodium and chloride concentrations in the sweat were $57.8 \mathrm{mEq} / 1$ and $64.3 \mathrm{mEq} / 1$, respectively.

E.E.G. revealed an intermittent abnormal pattern, sporadic high voltage slow wave of 2-5 cps and sharp wave or spike burst being induced in the bifronto-central areas by sleep activation.

\section{Clinical course}

After admission, his general condition looked to be fair, except for jaundice and malnutrition, but he was sometimes troubled with asthmatic bronchitis and diarrhea.

His growth was stunted and jaundice, pruritus, enlargement of the liver and abdominal distension were manifest throughout his life. At the age of 2 years 6 months, at which he died, he weighed only $7,050 \mathrm{~g}$ and measured $68 \mathrm{~cm}$ (normal values for 2 years 6 months, $11,920 \mathrm{~g}$ and $85 \mathrm{~cm}$.)

His physical and mental development was also markedly delayed. He was barely able to sit at the age of 1 year 3 months, but he could neither stand nor walk even at 2 years 6 months. The fontanel remained widely open and no epiphyseal centers appeared on roentgenogram.

The Gesell developmental diagnosis performed at the age of 1 year 9 months indicated also marked delay, showing the move mental age of 40 weeks, adaptation mental age of 40 weeks, language mental age of 28 weeks and individual-social mental age of 36-40 weeks. He could not yet speak even at the age of 2 years 6 months.

It was one of the characteristic features of the disease that there was persistent pruritus, which become more troublesome when icterus deepened markedly, or when bile salts were given orally on trial. Jaundice markedly varied in intensity throughout his life, showing $4.2 \mathrm{mg} / 100 \mathrm{ml}$ at the minimum to $28 \mathrm{mg} / 100 \mathrm{ml}$ at the maximum of the total bilirubin levels (Fig. 3). About twothirds to three-fourths of the total bilirubin was conjugated. The jaundice 
apparently deepened by the attacks of asthmatic bronchitis and grippal infection, although antibiotics such as Erythromycin or Tetracycline were also thought to play some role in the aggravation of jaundice. However, a distinct lowering of the serum bilirubin level was obtained by corticosteroid administration, although there was no complete disappearance. The slightly or moderately elevated GOT and GPT in serum also fluctuated, as shown in Fig. 3. The stool, which was observed usually 2-3 times and sometimes 6-8 times a day, was bulky, foul-smelling and light yellow to green white or sometimes green. From the age of 1 year, the skin became rough, thick, and brownish especially at the end of the extremities.

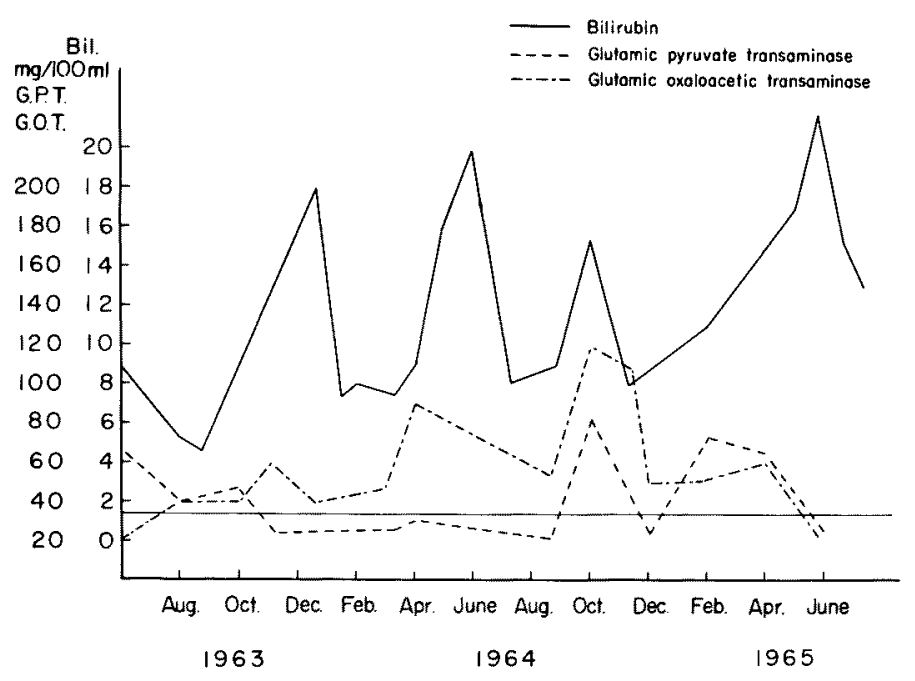

Fig. 3. Changes in serum bilirubin, GPT and GOT levels in our patient.

At the age of 2 years 6 months, explorative laparotomy was performed because of persistent unexplained obstructive jaundice. The bile passages were confirmed to be normal. Cholangiogram performed during the laparotomy showed a free passage into the duodenum.

After the operation, jaundice increased and unfortunately he died of acute pneumonia on July 27, 1965.

\section{Liver biopsy findings}

Liver biopsy was done on July 27, 1963 (7 months of age) and November 14, 1963 (11 months of age). Both histologic examinations indicated almost the same findings of a slight periportal fibrosis and numerous bile thrombi in many bile canaliculi. Otherwise, the lobular architecture was well preserved, and neither infectious hepatitis nor liver cell regeneration or necrosis was demonstrated (Fig. 4).

Necropsy (July 27, 1965, 2 years 6 months of age)

The liver was moderately enlarged, but normal in consistency. The surface 
was smooth and the cut surface revealed no abnormalities of the vessels, bile canal and parechymatous cells. The lobular architecture was well preserved.

The bile-bladder was of a thumb-tip size, slightly edematous and contained $1.5 \mathrm{ml}$ of sticky dark green bile. The bile ducts showed no abnormalities in appearance over the entire length.

The spleen was slightly enlarged, otherwise normal.

The pancreas, kidneys, brain, and endocrine organs were found all to be normal.

The lungs had atelectasis-like appearance, showing dark red-brown color. The cut surface revealed no special changes, but a moderate amount of foamy mucus was expelled from the bronchus on pressure.

\section{Histology}

Liver: The changes were apparently advanced as compared with those of the biopsied specimens obtained 2 years previously. Namely, diffuse periportal fibrosis became conspicuous, extending around the central veins in some part. Further, there were scattered foci of atrophy, degeneration and necrosis, but no regenerative nodules or pseudolobules (Figs. 5 and 6 ).

Bile pluggings were seen in bile canaliculi especially near the connective tissue septum. The sinusoids were narrowed on account of pericapillary edema and contained a few red cells, monocytes and polynuclear leucocytes. Kupffer's cells were swollen. Bile ducts were normal and portal tract showed a few cell infiltration.

Kidneys: Slight thickening of mesangium was seen; otherwise normal.

Lungs: A figure of patchy bronchopneumonia. There was no fibrosis.

Other organs: No abnormalities were observed.

Electronmicroscopic findings of the liver: Electronmicroscopic findings of the liver specimen examined at 8 months of age revealed distortion of mitochondrial limiting membrane, dilatation of bile canaliculi, blunted and diminished microvilli of the canalicular membrane and existance of a number of speckled encapsulated bodies of obscure origin (Fig. 7).

\section{Comment}

The clinical and biochemical characteristics of our patient are summarized as follows: 1) familial incidence, 2) fluctuated jaundice, which was initially found at the age of 6 months (over a half of bilirubin being conjugated), 3) marked steatorrhea, which probably preceded jaundice, 4) itching, 5) mental retardation 6) stunted growth with malnutrition and repeated asthmatic bronchitis and diarrhea, 7) short stubby hands and feet with thickened and brownish skin, 8) normal to low serum. cholesterol level and moderately elevated alkaline phosphatase, 9) slightly elevated serum GOT and GPT activities and elevation of $\alpha_{2}$ - and $\beta$-globulin, 10) marked retention of B.S.P., 11) increase of bile salts, especially cholic acid in the serum, 12) presence of bilirubin in urine and decreased fecal excretion of bilirubin and bile salts, 13) normal intra- and extrahepatic biliary passage, 14) 


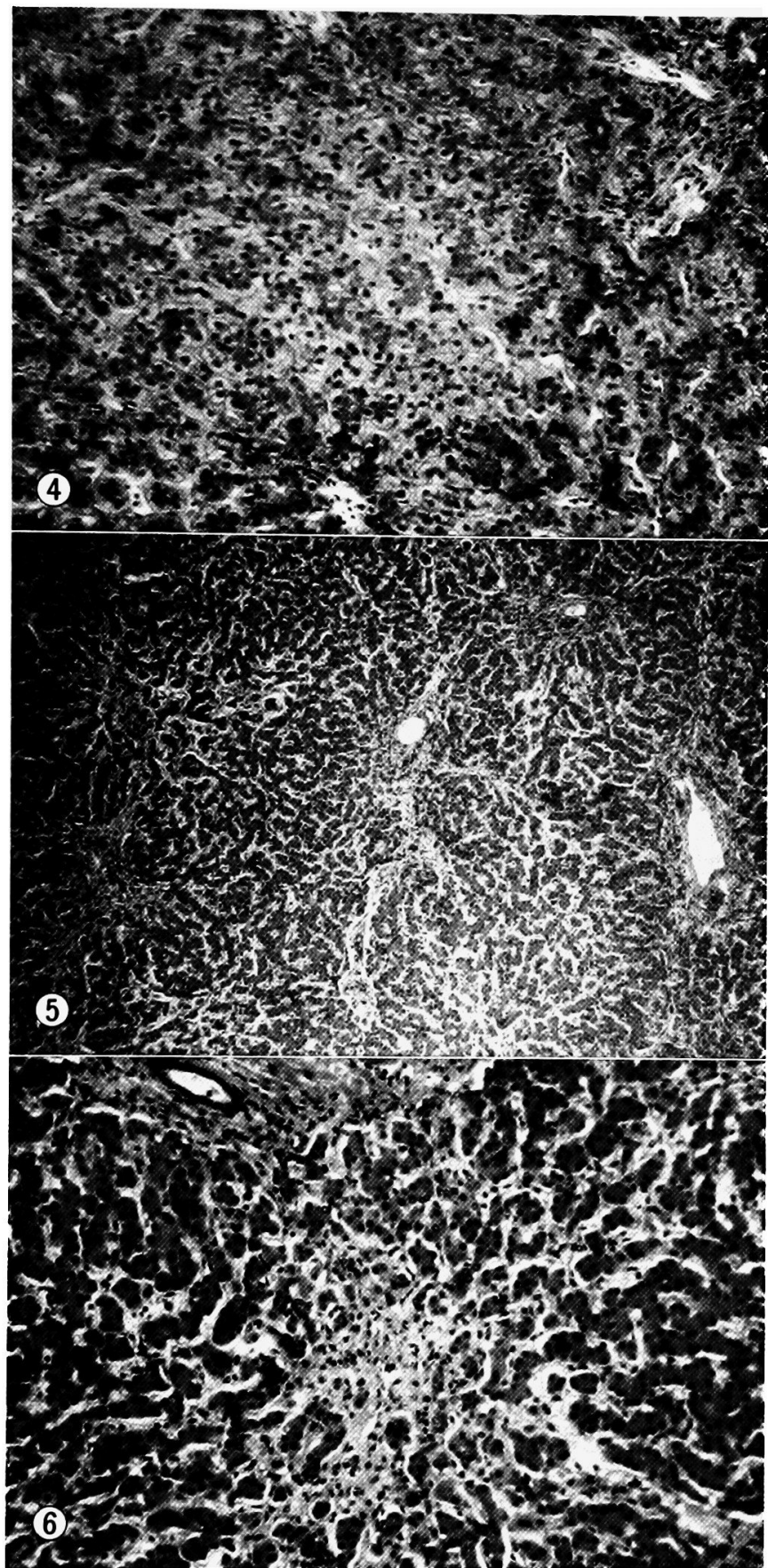

Fig. 4. Light microscopic finding of the liver biopsy specimen obtained on July 27, 1963 (7 months of age).

Fig. 5. Light microscopic finding of the liver at autopsy (July 27, 1965, 2 years 6 months of age)

Fig. 6. Light microscopic finding of the liver at autopsy. Note scattered foci of atrophy, degeneration, necrosis and fibrosis of the liver. 


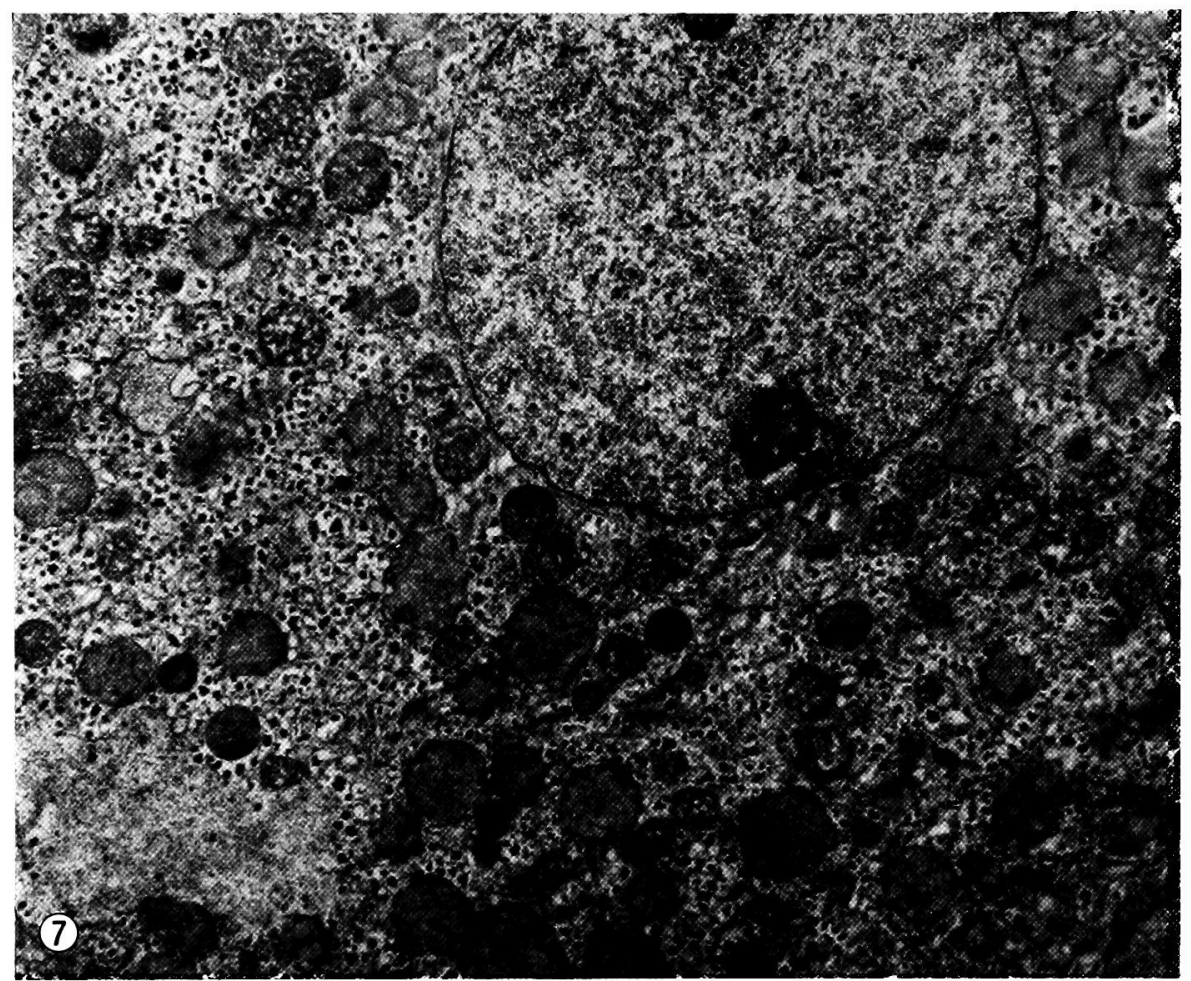

Fig. 7. Electron microscopic findings of the liver examined at the age of 8 months. Note distortion of mitochondrial limiting membrane and existence of a number of encapsulated speckled bodies of obscure origin.

periportal fibrosis and bile thrombi in the bile canaliculi (intrahepatic cholestasis) on light microscopic examination of the liver, and 15) distortion of mitochondrial limiting membrane, dilatation of bile canaliculi, microvilli reduced in number of the canalicular membrane and existence of a number of encapsulated bodies with speckled appearance on electronmicroscopic examination of the liver.

As mentioned above, our patient exhibited no abnormalities of the gall bladder and common bile duct at operation and at autopsy. Therefore, the diagnosis of extrahepatic biliary obstruction was ruled out. And further, normal hematologic data showed that the jaundice of our patient was not of hemolytic origin.

The presence of bilirubin in the serum readily differentiated the present case from one of Gilbert's disease, in which the defect may involve impairment in bilirubin uptake by the liver, and from one of Crigler and Najjar disease, in which the defect is inadequate glucuronide conjugation due to deficiency of glucuronyl transferase.

The increase in conjugated as well as unconjugated fractions of serum bilirubin of our patient suggested an impairment of bilirubin excretion at a postmicrosomal level. The defective hepatic excretion of conjugated bilirubin at a similar 
postmicrosomal level has been found to occur in both the Dubin-Johnson and Rotor's syndromes. However, the patients with the Dubin-Johnson syndrome do not have specific features of bile salt retention such as pruritus and steatorrhea, but do have characteristic pigments in the hepatic cells on liver biopsy. In the case of Rotor's syndrome, the clinical features are quite similar to those in the DubinJohnson syndrome except for the absence of the pigments in the liver cells. In addition, histologic evidence of bile stasis has ever been observed in neither of these two conditions. These findings were different from those of our patient and our own case could not be one of the Dubin-Johnson or Roter's syndrome.

Recently, familial neonatal hepatitis has been reported with increasing frequency. ${ }^{8-11}$ In this respect, early onset of jaundice in our patient made a distinction from the symptom in neonatal hepatitis necessary. Our patient was not considered to have neonatal hepatitis from the following points: 1) in our patient, no abnormal findings were observed during neonatal period, and jaundice first appeared at the age of 6 months, being preceded by steatorrhea;2) the histologic findings of the liver did not indicate giant cell changes, marked periportal cell infiltrations and marked cell degenerations which are characteristic of neonatal hepatitis; 3) the jaundice in our patient fluctuated throughout his life, while that in most of neonatal hepatitis improved with lapse of time or showed no marked fluctuation; and 4) in our patient, there was marked mental and growth retardation, which does not belong to the symptoms of patients with neonatal hepatitis.

Congenital absence of the intrahepatic bile duct, which was first described by Ahrens, et al. ${ }^{12}$ and further by Haas and Dobbs, ${ }^{13}$ was also considered to be different from our patient's disease because xanthomatosis, high cholestrol level and absent intrahepatic bile duct etc., have been reported in the former, while such symptoms were not observed in our patient.

However, our patient had some apparent similarities to so-called familial benign recurrent intrahepatic cholestatic jaundice reported by Summerskill et al. ${ }^{14,15}$ Tygstrup ${ }^{16}$ and Schapiro and Jsselbacher., ${ }^{17}$ etc. The main clinical feature of patients with these benign recurrent jaundices consited in recurrent jaundice, which was usually associated with a history of pruritus, dark urine, clay-colored stools and weight loss. The serum bilirubin levels were elevated, the major increase being in the conjugated fraction. The serum alkaline phosphatase levels were also significantly increased. Liver biopsy showed marked bile stasis and some cellular infiltration of portal areas. Despite of numerous attacks beginning at an early age, there was general health between attacks, good prognosis and no impairment of liver function tests.

These findings of the patients with benign recurrent jaundice were similar to those of our patient in biochemical features, but differed in the age of onset, severity and prognosis, showing that both diseases probably belong to different entities.

In recent time, however, cases with similar clinical history and findings, and laboratory data to those of our case have been reported by Clayton et al.,' Gray 
and Saunders ${ }^{2}$ and Juberg et al. ${ }^{\mathbf{3}}$

Clayton $e t a l .{ }^{1}$ reported 'Byler's disease; fatal familial intrahepatic cholestasis', which was observed in six members of four Amish sibships. The clinical course of these cases was characterized by early onset of loose foul-smelling stools, 'attacks' of jaundice, hepatosplenomegaly, dwarfism, deaths between 17 months and 8 years, in 4 of 6 cases, and biochemical findings of hyperbilirubinemia (over a half being direct-reaction pigment), serum alkaline phosphatase elevation and normal to low serum cholesterol. Jaundice appeared from one to 8 months after the onset of gastrointestinal symptoms in all cases, and bile analysis in a 6-month-old affected child showed an increased relative proportion of bilirubin monoglucuronide and dihydroxy bile salts. Liver biopsy revealed intrahepatic cholestasis and early fibrosis and electron microscopic examination demonstrated intracellular encapsulated reticulum-like material.

These clinical history and findings, and biochemical and histological characteristics are almost similar to those of our patient mentioned above.

However, there was no description of mental retardation in Clayton's cases, which was manifest in our case and Juberg's cases.

Gray and Saunders ${ }^{2}$ described two sisters both of whom died under 3 years of age from a malignant variety of intrahepatic cholestasis due to a difficulty in bile excretion. The clinical and biochemical characteristics of these two cases seemed to be similar to those of our case and the cases of Clayton et al. and Juberg et al. However, the time of onset was so early as at 6 and 7 weeks of age, while most of the similar cases reported by others did not develop jaundice in the first third of the first year. And further, in these cases as well as in the cases of Clayton et al., there was neither mental retardation nor steroid induced reduction in the serum bilirubin level. Serum bile acid levels indicated dihydroxy, $30.4 \mu \mathrm{g} / \mathrm{ml}$; trihydroxy, $27.9 \mu \mathrm{g} / \mathrm{ml}$.

Juberg et $_{\mathrm{al}}{ }^{3}$ also described a severe form of cholestasis beginning in infancy, apparently progressive in nature and resulting in significant impairment of growth and development in four siblings. The time of onset, development of the disease and biochemical characteristics were almost similar to those in the family of Clayton et $a l .{ }^{1}$ and our case.

In addition, there was mental and growth retardation in all, although the degree was more marked in our patient. However, steatorrhea was not a prominent problem, although the stools were abnormal in color and to some extent in consistency. Cholesterol levels in the serum of the four siblings were slightly elevated. The finding was not present in our patient and Clayton et al.'s cases. ${ }^{1}$

The reports mentioned above indicated that the conditions of our patient and of the patients of Clayton et al., ${ }^{1}$ Gray and Saunders ${ }^{2}$, and Juberg et al. ${ }^{\mathbf{3}}$ were probably identical except for some minor differences. In other words, a probably new disease was reported from three different areas of the world (U.S.A., England and Japan), showing that the disease was not limited to one race or one family.

The pathogenetic mechanism of the disease remains obscure. However, the 
disease is very likely to be genetic, because of its familial nature and identical clinical course. On the basis of their detailed studies of the affected families, Clayton et al. and Juberg et al. suggested that autosomal recessive inheritance probably accounted for the most likely ectiology. Marked bromsulphalein retention is apparently due to a failure of either conjugation or excretion.

Clayton et al. ${ }^{1}$ suggested that a metabolic error of bile salts may be involved in the pathogenesis, because analysis of the bile in one patient showed an increased relative proportion of bilirubin monoglucuronide and dihydroxy bile salts, and hyperbilirubinemia in one patient cleared with cholestyramine.

Gray et al. found in his one case that the glucuronide formed was only $25 \%$, whereas the alkali-stable fraction was $60 \%$ of the total conjugated bilirubin, and suggested that there is reduction in the glucuronyl transferase activity and/or a failure in the alternative pathway of conjugation in addition to the block to excretion of the conjugates.

Juberg et $a l .^{3}$ stated that there was marked bromsulphalein retention and most of bilirubin in the serum of their patients was conjugated, and trihydroxy bile salts were elevated, and suggested a defect in the excretory mechanism of bilirubin located between the sites of conjugation and the lumen of bile ductule.

As mentioned above, our own case showed also marked bromsulphalein retention, preponderance of conjugated bilirubin and elevation of cholic acids, suggesting a defect in the same sites as in Juberg's case.

Electron microscopic examination of the liver of our patient revealed distortion of mitochondrial limiting membrane, dilatation of the bile canaliculi, blunted and fewer microvilli of the canalicular membrane and existence of a number of encapsulated bodies with a speckled appearance, which were of obscure origin. However, it remains undetermined whether these changes, especially encapsulated bodies with speckled appearance are primary, and the key to settle the pathogenetic mechanism of the disease is not yet discovered.

\section{References}

I) Clayton, R.J., Iber, F.L., Ruebner, B.H. \& Mckusick, V.A. Byler's disease: Fatal familial intrahepatic cholestasis in an Amish kindred. J. Pediat., 1965, 67, 1025-1028.

2) Gray, O.P. \& Saunders R.A. Familial intrahepatic cholestatic jaundice in infancy. Arch. Dis. Childh., 1966, 41, 320-328.

3) Juberg, R.C., Holland-Moritz, R.M., Henley, K.S. \& Gonzalez, C.F. Familial intrahepatic cholestasis with mental and growth retardation. Pediatrics, 1966, 38, $819-836$.

4) Sherlock, S. Biliary secretory failure in man. The problem of cholestasis. Ann. intern. Med., 1966, 65, 397-408.

5) Pereira Lima, J.E., Utz, E. \& Roisenberg, I. Hereditary nonhemolytic conjugated hyperbilirubinemia without abnormal liver cell pigmentation. Amer. J. Med., 1966 , 40, 628-633.

6) Eberlein, W.R. A simple solvent-partition method for measurement of free and conjugated bilirubin in serum. Pediatrics, 1960, 23, 878-885.

7) Kier, L.C. A method for the simultaneous quantitative determination of cholic acid and deoxycholic acid. J. Lab. clin. Med., 1952, 40, 755-762. 
8) Adams, F.H., Anderson, R.C. \& Richdorf, L.F. Four siblings with hepatic disease leading to cirrhosis. Amer. J. Dis. Child., 1952, 84, 168-174.

9) Hsia, D.Y., Boggs, J.D., Driscoll, S.G. \& Gellis, S.S. Prolonged obstruction jaundice in infancy. Amer. J. Dis. Child., 1958, 95, 485-491.

10) Cassady, G., Morrison, A.B. \& Cohen, M.M. Familial giant cell hepatitis in infancy. Amer. J. Dis. Child., 1964, 107, 456-469.

11) Burkhardt, S., Gugler, E. \& Laissue, J. Die familiäre neonatale Hepatitis. Z. Kinderh., 1967, 98, 1-15.

12) Ahrens, E.H., Jr., Harris, R.C. \& MacMahon, H.E. Atresia of the intrahepatic bile ducts. Pediatrics, $1951,8,628-647$.

13) Haas, L. \& Dobbs, R.H. Congenital absence of the intrahepatic bile ducts. Arch. Dis. Childh., 1958, 33, 396-402.

14) Summerskill, W.H.J. \& Walshe, J.M. Benign recurrent intrahepatic "obstructive" jaundice. Lancet, 1959, 2, 686-690.

15) Summerskill, W.H.J. The syndrome of benign recurrent cholestasis. Amer.J. Med., 1965, 38, 298-305.

16) Tygstrup, N. Intermittent possibly familial intrahepatic cholestatic jaundice. Lancet, 1960, 1, 1171-1172.

17) Schapiro, R.H. \& Jsselbacher, K.J. Benign recurrent intrahepatic cholestasis. New Engl. J. Med., 1963, 268, 708-711. 